Journal Name: Music Education Research

Habitus and flow in primary school musical practice: relations between family musical cultural capital, optimal experience and music participation.

Rafael Valenzuela* and Nuria Codina

Department of Social Psychology, University of Barcelona, Barcelona, Spain

*rvalenga7@alumnes.ub.edu

Rafael Valenzuela. Degree in Social Psychology in the Pontificia Universidad Católica del Perú (PUCP, 2005). MSc in Leisure Studies in the University of Deusto, Bilbao (UD, 2009). Teacher in the PUCP from 2005 to 2008, he manages programs of corporate volunteering and cultural participation since 2000 and has been invited to teach specific sessions in UD and UB since 2009. He takes part in the Research Group PsicoSAO (2009 SRG 210), supported by the regional government of Catalonia (Spain) and is currently enrolled in the $\mathrm{PhD}$ in Cultural Management in the UB.

Nuria Codina. Degrees in Philosophy and Educational Sciences (1985) and in Psychology (1986), both in the University of Barcelona (UB). PhD in Psychology (UB, 1990). University Professor in the UB since 1991, she has been visiting scholar in the universities Paul Valery (Montpellier, France), Universidade Estadual de Campinas, Pontificia Universidade Católica de Rio Grande do Sul, Pontificia Universidade Católica de São Paulo (Brasil), Universidad Nacional Autónoma (México), and University of Georgia (USA). She coordinates the Research Group PsicoSAO (2009 SRG 210), supported by the regional government of Catalonia (Spain), also being member of OcioGune Leisure Research Network (University of Deusto, Spain), as well as of the Social Psychology Teaching Innovation Group in the UB (2009 GID-UB/15).

Acknowledgements.

This contribution received the financial support of the Ministry of Economy and Competitiveness from the Government of Spain (Project code: EDU2012-39080-C07-04). The English language revision has been possible due to the financial support of the Commissioner from Universities and Research from the Government of Catalonia, through PsicoSAO (2009 SRG 210; consolidated research group in Social, Environmental and Organizational Psychology). The authors express their thanks to Christopher Gladwin for his invaluable help with the English language manuscript. Also to Fundació Privada de L'Auditori i L'Orchestra for hosting this research project, in particular, to Assumpció Malagarriga, head of the educational department.

\title{
Habitus and flow in primary school musical practice: relations between family musical cultural capital, optimal experience and music participation.
}

Based on Bourdieu's idea that cultural capital is strongly related to family context, we describe the relations between family musical cultural capital and optimal experience during compulsory primary school musical practice. We analyse whether children from families with higher levels of musical cultural capital, and specifically with regard to active engagement in musical practice, obtain more optimal experience from primary school musical practice than their peers, thus improving their chances of sustained engagement in musical practice in their personal lives. We draw from Csikszentmihalyi's theory of flow to better understand how intrinsic motivation and absorption can foster children's perseverance in musical practice and the consequent acquisition of new, relevant musical cultural capital. Results based on a sample of 186 pupils suggest that, in order to optimise the impact on the development of new musical cultural capital, state educational syllabuses should harness the dynamics of the diverse family contexts.

KEYWORDS: Cultural capital; family; music education; flow; social psychology, leisure. 


\section{Introduction}

Buying a guitar may take just a few minutes but learning how to play it can take years. Whatever the instrument or medium, acquiring, mastering and expressing knowledge and skills, inherent to any specific kind of musical practice, are tasks that take considerable time and effort. According to Bourdieu's conceptualization of 'cultural capital, field and habitus' (1977b, 1990b), the effort needed to incorporate cultural capital of a specific domain is affected by the initial provision of that kind of capital, 'inherited' by children through early socialization in the core of their families. When eleven- to twelve-year-old pupils have to deal with primary school musical practice, a 'field' embedded in western tradition, the educational system demands from them 'cultural competence' and 'a relationship of familiarity with culture which can only be produced by family upbringing' (Bourdieu, 1977a, 493). Consequently, children from families with higher levels of cultural capital in the area of musical practice, given their earlier access to related knowledge and skills and their 'habitus' or familiarity with musical practice, may well feel more comfortable playing an instrument or singing in a choir, and obtain greater optimal experience from these activities. As explained by Burnard (2012), following on from Bourdieu, this may well happen because children from privileged backgrounds are more likely to have received cultural training from relatives or even hired professionals, and this provides them with a 'habitus' or sense of what is comfortable or natural, highly compatible with the values of the dominant institutions or 'fields'.

The 'habitus' has been described as a 'feel for the game' or a 'practical sense' (Bourdieu, 1990b, 66) and defined as a 'system of durable dispositions' and 'principles which generate and organize practices', 'without presupposing a conscious aiming at ends' (Bourdieu, 1977b, 72, 1990b, 66). A 'habitus' consisting of tastes, habits, norms, values and traditions is formed and developed in ways that people are not even fully aware of, but may have important influences on how people manage their surroundings or activities (Bourdieu and Passeron, 1990). However, as Bouveresse (1999) points out, these influences should not be understood as mechanisms but rather 
in terms of diverse strategies and a 'regulated disposition to generate regulated and regular behaviour outside any reference to rules' (Bourdieu, 1990a, 65). While the above characterizations support Bourdieu's notion of 'habitus', avoiding both mechanistic objectivism and existentialist subjectivism, Margolis (1999) has noted that in order to strengthen the contribution of the concept it would be beneficial to point out and describe specific cognitive processes through which the 'habitus' supposedly organises its logic of practice.

Below we establish several theoretical links between cognitive processes that can be related to the notion of 'habitus' but which are also crucial for generating optimal experience and sustained engagement in musical practice.

\section{The onset of intrinsic motivation: family musical cultural capital and initial attitudes towards musical practice}

Music pedagogues are beginning to acknowledge that if pupils are to achieve and develop intrinsic motivation and enduring engagement in musical practice, they must have a strong musical selfconcept (Lamont, 2011). However, as is well known, prior formal or informal music education and its corresponding musical background can greatly condition people's experiences in the field of music learning (Moore, 2012) and sociocultural context can easily act as a constraint or enable people's perception of agency while learning music (Wiggins, 2011). One of the main difficulties of developing primary school music education syllabuses resides in the fact that not all pupils come from home backgrounds in equal conditions as regards musical cultural capital and prior experience in musical practice, because as Ilari, Moura and Bourscheidt (2011) have argued, musical parenting style and family cultural background are closely interrelated and parents shape their own lives around the act of parenting, which includes the transmission of cultural values, beliefs and skills through participation in daily cultural activities. 
Children from families with higher levels of active engagement in musical practice, whose relatives play, sing, or compose, may have a greater probability of experiencing music within the context of regular family activities and through significant agents of socialization, thus facilitating their identification with musical practice. As seen from the perspective of Bourdieu and Passeron (1990), the study of the processes through which this favourable musical self-concept is built up is inherently complex, because the initial formation of the 'habitus' and the corresponding transmission of cultural capital occur during early socialization at the core of the family and without the individual being fully aware of the process. Also Mead (1934) understands that until a certain age, given their limited self-awareness, children vicariously incorporate or reject pre-set attitudes towards different phenomena present in their families. Some children have to conform or react to positive attitudes towards musical practice, others to negative ones, consequently limiting the extent to which they will be able to feel interested in music overall and identify with musical activities.

The notion of 'habitus', so closely linked to attitudes and interests, can be helpful in explaining willingness to practice music and -something more central to our research -how this willingness is related to intrinsic motivation towards musical practice, given that the latter is a key aspect of learning processes (Deci, 1971), and of music learning processes in particular (Bakker, 2005; Lamont, 2011).

It remains to be assessed through experimental research whether intrinsic motivation in eleven- and twelve-year-old primary school pupils can be targeted by music teachers and developed through the enjoyment of musical practice itself, rather than remaining exclusively dependent on prior early socialization and identifications associated with the musical attitudes and aptitudes existing at the core of pupils' families. In the case of pupils from families where these positive attitudes and aptitudes are not much in evidence, music teachers play a more central role in generating new intrinsic motivation towards musical practice, a fresh willingness to practice music 
and more positive attitudes towards music, through the development of attractive class activities and the role model the teachers themselves provide for musical enjoyment.

\section{The process leading to absorption: clear goals, feedback, balance, control and concentration}

In 1988 Csikszentmihalyi began to develop a conceptualization of flow which posits that optimal experience or flow is a state of psychological equilibrium resulting from an optimal balance between a high degree of challenge, posited by a motivating situation and a corresponding high level of skill or competence a person is capable of performing at in that specific domain. According to Bakker (2005), researchers have been consistent in underscoring three main components of optimal experience, namely intrinsic motivation, absorption and enjoyment. These three components shape optimal experience as a process, as it is possible to visualize them as a theoretical sequence in which intrinsic motivation leads to absorption, while absorption leads to enjoyment. As Csikszentmihalyi (1991) has pointed out, absorption is intimately related to the experiences of concentration, perceived control and balance, which individuals are more likely attain through access to clear, attainable goals and direct, immediate performance feedback. Consequently, significant agents of socialization, such as parents and relatives - and also primary school music teachers, given their propinquity and salient role in music education - can promote children's absorption in musical practice by providing feedback, support, and clear goals that present each and every child with optimal challenges, i.e. challenges on a par with their personal skill and competence levels. The knowledge domain of western musical practice, i.e. the knowledge and skills required to play, sing or compose, may seem a natural and comfortable area of learning for those children who have at least been introduced vicariously to it, while it may seem the opposite for others who feel less connected to it, thus limiting their potential levels of control, balance and concentration and - consequently - optimal experience. As McIntyre (2007) has noted 
with regard to Csikszentmihalyi's study of creativity (which is intimately tied in with both intrinsic motivation and flow), individual attributes are not the only factor with a critical influence on the incidence of creativity; the attributes of the knowledge domain and the field or social organisation corresponding to that domain are also critical. Consequently, this provision of personalised challenges may not be an easy task for the teacher, but it is important for absorption, given the students' heterogeneous levels of 'practical sense' in relation to musical practice.

While considering the central importance of absorption in optimal experience, another challenge faced by primary school music teachers is that, as postulated by Lamont (2011), children's motivation towards musical practice may initially be governed by extrinsic motives, such as the desire to please or impress others, which naturally limits the achievable levels of absorption in the classroom, because paying attention to heteronomous figures while seeking extrinsic approval contrasts strongly with the deep focus and exclusive concentration on the task at hand which absorption demands. Only later on may school students become more absorbed, autonomous and intrinsically motivated with regard to musical practice, but, as argued by McIntyre $(2007,5)$, given the 'circular causality' of autotelic experience, 'any one of the components in the system' (i.e. the domain, the field or the person) and 'the system as a whole' can generate its occurrence. In fact, the provision of personalised challenges on their own, on a par with a child's skills and compounded by extrinsic motives, could well be enough to initiate the autotelic or flow experience, with intrinsic motivation following naturally, instigated by the desire to re-enter a state of optimal experience.

\section{Obtaining enjoyment: the give and take of sustained engagement}

People experience flow or optimal experience when they tackle challenges that are in balance with their own skill or competence levels. Tasks that seem too hard to tackle may become frustrating, whereas tasks that are too easy may be deemed as boring (Csikszentmihalyi, 1991). However, as new skills are developed and competence is enhanced, through engagement in practice, optimal 
challenges gradually increase in difficulty and complexity, and the sense of reward and the enjoyment of tackling them grow accordingly. In many cases, people who experience flow want to continue to experience it and, consequently, they remain engaged in the activities that target it until a habit is created in some cases.

Csikszentmihalyi (1991) and Stebbins (2001) have both distinguished between the shortterm pleasure of casual experiences and the deep sense of reward and accomplishment a person experiences as a result of successfully tackling intrinsically motivating and gradually growing challenges, through the investment of considerable amounts of time and effort in order to develop the skills and competences required to tackle them. As conceptualized by Stebbins (1992) in his socalled serious leisure perspective, a person pursuing the experience of continuous flow characteristically takes a path on which he or she strives to incorporate and express new knowledge and skills relevant to the activity that generates this deep enjoyment. It is worth mentioning that the adjective 'serious' in the term 'serious leisure' does not have the typical connotations of 'tedious' or 'boring', but rather refers to a certain degree of earnestness and importance ascribed by people to their own engagement in the activity (Stebbins, 1992).

In line with Csikszentmihalyi (1991) and Stebbins (2001), we argue that the enjoyment reported by those who experience flow can be understood as a symptom or the fruit of the successful combination of three factors consisting of an intentionality rooted in intrinsic motivation, an attention process characterized by absorption, and the tackling of gradually growing optimal challenges - which bring about self-actualization and growth.

On the other hand, this enjoyment obtained from the activity can also serve as a source of positive attitudes to future engagement and this is very important in the case of children from families with lower levels of musical cultural capital, who have less chance of deriving enjoyment from musical practice before attending primary school music class. For them, in this respect, 
enjoyment is also expected to engender higher levels of intrinsic motivation and a greater willingness to practice music in the future.

To promote optimal experience among pupils, we contend that primary school music teachers have to take three main courses of action: first of all, assessment, strengthening and developing fresh intrinsic motivation and interest in music and its practice; secondly, correct assessment of the pupils' various levels of skill, so as to be able to present them with optimal challenges that afford a sense of balance and control, promoting concentration and absorption; and thirdly, teachers should provide a role model for the enjoyment of musical practice, in order to support the pupils' on-going engagement.

To frame our research, we asked ourselves the following question: what roles do family musical cultural capital and optimal experience in the primary school music classroom play in fostering music participation among eleven- and twelve-year-old children? The broad aim of the study was to assess the initial stages of musical practice among eleven- and twelve-year-old primary school pupils. First, we described the relationship between family musical cultural capital and optimal experience in compulsory primary school musical activities, such as playing an instrument or singing in a choir, to test out Bourdieu's assumption that members of families with higher cultural capital in a certain 'field' will feel more comfortable and natural expressing themselves in that 'field', thus enhancing their chances of optimal experience. Second, we described the relationship between optimal experience in school musical activities and engagement in musical practice (playing an instrument or singing in a choir) and concert attendance, controlling for family musical cultural capital to test the possible mediating effect of children's 'habitus' on flow and the effective fostering of sustained engagement in musical practice in their personal lives. 


\section{Method}

\section{Participants}

The research sample consisted of 186 primary school pupils aged eleven and twelve years old.

Children were selected from this age group because they have already experienced initial socialization in the family environment but are still at a relatively early stage in their acquisition of cultural capital and their experience of musical practice and participation. On the other hand, they were old enough as respondents to be able to cope with the level of complexity of the research instrument. Our sampling method was designed to yield participants who experienced sufficiently high levels of flow during school musical practice. Through the educational department of a public auditorium in Catalonia, we contacted eight primary schools that were taking part in the auditorium's music education programme, which included performances by children's choirs with an orchestra.

\section{Procedure}

We interviewed the music teachers and instructed them on how to use the research instrument with their pupils in eight primary school classes. Pupils were allowed one entire standard school music class lasting forty-five minutes to complete the questionnaire with replies based on their own experience in school musical practice. We attended two of these sessions to check the suitability of the questionnaire set for teachers and pupils, as regards the level of difficulty of the tasks of supervision and completion.

\section{Instrument}

We designed a short questionnaire to assess family musical cultural capital, children's self-reported level of interest in music and the extent to which they liked to play an instrument or sing. With the aim of assessing specific aspects of the children's habitus, this questionnaire included six 
statements, phrased in the third person, such as 'the person has a great interest in music', which expressed positive attitudes towards music and some aspects of music participation as highly liked or present in their lives. We operationalized family musical cultural capital as the extent to which participants reported having musicians as relatives, assessed through the participants' perceived identification with the statement 'the person has musicians as relatives', which is an unambiguous and easy-to-report measure of the presence of family cultural capital in relation to the field of musical practice in the western tradition. Participants had to rate their identification with the initial statements on a 6-point scale (not at all like me [=1], unlike me [=2], somewhat unlike me $[=3]$, somewhat like me $[=4]$, like me $[=5]$, and totally like me $[=6])$. To measure intrinsic motivation, absorption and enjoyment, we adapted three elements derived from the Work-Related Flow Questionnaire (WOLF) (Bakker, 2001, 2005). We also adapted Martin and Jackson's short flow questionnaire (2008) to assess characteristic aspects of optimal experience such as clear goals, performance feedback, balance, control and concentration. Lastly, also to measure balance, we adapted one more item from French, Caplan and Harrison (1982), to be exact, 'I have enough skills to carry out the tasks properly', as reported by Bakker (2005), and included it in the short flow section of the instrument. All the issues mentioned above were assessed on a 6-point scale, ranging from 'I totally agree' (6 points) to 'I totally disagree' ( 1 point). Ten other items covering a variety of factors such as willingness to participate, sense of reward, perceived competence and obligation were included in the questionnaire to gather information on specific processes relevant when attempting to understand optimal experience during music education. These items were rated according to their reported frequency on a 6-point scale, ranging from never $(=1)$ to always $(=6)$. Lastly, we assessed musical practice as regards playing an instrument and singing in a choir, and cultural participation in the form of attendance at classical and popular music concerts over the previous twelve months, dichotomously coding affirmative or negative replies as 1 or 0 , respectively. The content validity of all items was reviewed with the expert assistance of the 
director of the educational programme through which we contacted the participants, and also one music school director and two music education specialists engaged professionally in primary school music teaching.

\section{Analysis}

As a first step, nonparametric Mann-Whitney tests were used to compare musical practice, concert attendance and optimal experience during school musical practice among pupils from families with, respectively, high and low levels of musical cultural capital, defined as the extent to which participants reported having musicians as relatives. We present means and standard deviations for intrinsic motivation, absorption, enjoyment, and their averaged out overall flow score, and also for those items describing pupils' levels of musical practice and participation as regards playing an instrument, singing in a choir and attending classical and popular music concerts (Table 1).

Secondly, to analyse the correlations between optimal experience during school musical practice and music practice and participation, controlling for the effect of family musical cultural capital, we report nonparametric Spearman correlations between both family musical cultural capital and optimal experience in school musical practice and measures of engagement in musical practice, such as playing an instrument or singing in a choir, and indicators of music participation such as classical or popular concert attendance (Table 2). In this way we are able to descriptively account for the strength of the associations of both optimal experience and family background with music practice and participation. Furthermore, we analyse partial correlations between flow measures and music participation, controlling for family musical cultural capital, which permits further insights into the importance of this kind of capital and the corresponding 'habitus' for the consolidation of music participation.

Thirdly, to analyse the processes involved in fostering intrinsic motivation and absorption during school musical practice, we describe their nonparametric Spearman correlations with key 
aspects that our theoretical framework suggested were critical for flow. These correlations are presented in a visual model (Figures 1 and 2), displayed according to the theoretical organisation of these key aspects leading to optimal experience, and arguing in favour of construct validity.

\section{Findings}

\section{Flow and music participation in relation to family musical cultural capital}

Pupils from families with higher levels of musical cultural capital took part in musical activities in proportionally greater numbers and also reported higher levels of optimal experience in school musical practice than their peers from 'non-musical families' (Table 1). Pupils coming from 'musical families' scored higher in intrinsic motivation, absorption, enjoyment, flow average, playing an instrument, singing in a choir, and attending concerts as compared to their peers from ‘non-musical families'. Nonparametric Mann-Whitney comparisons confirmed significant differences between these two groups for six of the eight tested variables (Table 1).

\section{[Table 1 near here]}

Table 1: Pupil flow and pupil music participation in relation to family musical cultural capital

\section{Correlations between flow, family musical cultural capital and music participation}

The three main components of the flow construct showed strong internal consistency as observed through their correlations (Table 2). In our sample, out of the three main aspects of flow in school musical practice, only enjoyment was associated with the two measures of musical practice (Table 2), playing an instrument $\left(\mathrm{r}_{\mathrm{s}}=.26, \mathrm{p}=.002\right)$ and singing in a choir $\left(\mathrm{r}_{\mathrm{s}}=.18, \mathrm{p}=.033\right)$. All components of flow correlated with popular music concert attendance, while none of them correlated with classical music concert attendance. Interestingly enough, flow and family musical cultural capital both displayed associations with the two measures of musical practice, almost identical in strength and 
significance. There were correlations between family musical cultural capital and playing an instrument $\left(\mathrm{r}_{\mathrm{s}}=.27, \mathrm{p}=.001\right)$ and singing in a choir $\left(\mathrm{r}_{\mathrm{s}}=.19, \mathrm{p}=.031\right)$, but also both measures of concert attendance, popular $\left(\mathrm{r}_{\mathrm{s}}=.23, \mathrm{p}=.004\right)$ and classical $\left(\mathrm{r}_{\mathrm{s}}=.25, \mathrm{p}=.002\right)$. Family musical cultural capital also correlated with intrinsic motivation $\left(\mathrm{r}_{\mathrm{s}}=.19, \mathrm{p}=.017\right)$, enjoyment $\left(\mathrm{r}_{\mathrm{s}}=.34, \mathrm{p}=.000\right)$ and flow average $\left(\mathrm{r}_{\mathrm{s}}=.23, \mathrm{p}=.003\right)$. However, it did not correlate with absorption.

\section{[Table 2 near here]}

Table 2: Spearman correlations between flow in musical practice, family musical cultural capital and music participation

Finally, to shed some light on the importance of family background as a basic concern of primary school music teachers when encouraging music participation, we ran partial correlations between the three measures of flow in school musical practice and the four measures of music participation, but this time controlling for the effect of family background. Popular music concert attendance was the only measure of music participation to remain significantly associated with the flow measures of enjoyment $\left(\mathrm{r}_{\mathrm{s}}=.24 ; \mathrm{p}=.006\right)$ and intrinsic motivation $\left(\mathrm{r}_{\mathrm{s}}=.20 ; \mathrm{p}=.006\right)$ within school musical practice.

\section{The onset of intrinsic motivation}

Nonparametric Spearman correlations were used to explore the associations among those key processes that according to our theoretical framework could directly and indirectly foster intrinsic motivation towards musical practice. As predicted, family musical cultural capital was associated with positive attitudes towards music and its practice (Figure 1), correlating with general interest in music $\left(\mathrm{r}_{\mathrm{s}}=.30 ; \mathrm{p}=.000\right)$ and a liking for musical practice $\left(\mathrm{r}_{\mathrm{s}}=.36 ; \mathrm{p}=.000\right)$. Both these positive attitudes, which, as stated previously, can be considered aspects of children's 'habitus', correlated highly with each other $\left(\mathrm{r}_{\mathrm{s}}=.61 ; \mathrm{p}=.000\right)$. When averaged out to compute a new target variable, this new variable displayed an even stronger correlation with family musical cultural capital $\left(\mathrm{r}_{\mathrm{s}}=.39\right.$; $\mathrm{p}=.000$ ), which can be understood as indicating strong internal consistency between family musical 
cultural capital, the 'habitus' and its attitudinal components. Moreover, these attitudes were associated with the willingness to participate in musical practice. As predicted by the theoretical framework, interest in music $\left(r_{s}=.27 ; p=.000\right)$, a liking for musical practice $\left(r_{s}=.29 ; p=.000\right)$, and their average $\left(r_{s}=.31 ; p=.000\right)$ all showed significant correlations with the willingness to participate in musical practice. In turn, this willingness to practice music also correlated, as predicted, with intrinsic motivation towards musical practice $\left(\mathrm{r}_{\mathrm{s}}=.28 ; \mathrm{p}=.000\right)$.

In Figure 1, all the pairs of adjacent variables display a stronger and more significant correlation with each other than other pairs of variables farther apart in the model. For example, the direct association between family musical cultural capital and intrinsic motivation in school musical practice is not as strong as its associations with positive attitudes towards music or a willingness to practice music, which, in turn, most strongly correlates with intrinsic motivation.

To test the impact of family musical cultural capital on the variables included in Figure 1 (the onset of intrinsic motivation), we conducted Mann-Whitney comparisons, which confirmed that children coming from 'musical families' and 'non-musical families' differed significantly in all variables: interest in music $(U=2490,0 ; p=.000)$, liking for musical practice $(U=2367,5 ; p=.000)$, willingness to participate in musical practice $(U=3101,0 ; p=.040)$ and intrinsic motivation towards musical practice $(\mathrm{U}=2721,5 ; \mathrm{p}=.020)$.

\section{[Figure 1 near here]}

Figure 1: The onset of intrinsic motivation

\section{The process leading to absorption}

According to our theoretical framework (Csikszentmihalyi, 1991; Bakker 2005; Martin and Jackson, 2008) clear goals and feedback promote balance and perceived control, which are key ingredients of pupils' capacity for absorption, and are also essential to concentration. As predicted, the clearness of the goals of musical practice and immediate performance feedback correlated with 
concentration, perceived control and balance (Figure 2). Goals, feedback, balance, control, and concentration all had strong correlations with each other and strong correlations with absorption, which suggests - as predicted by the theory - that they may be acting as a system promoting absorption.

\section{[Figure 2 near here]}

Figure 2: The process leading to absorption

In contrast to Figure 1, Mann-Whitney analyses did not reveal significant differences between children from 'musical' and 'non-musical families' in all the Figure 2 variables. Only feedback $(U=3002,0 ; p=.045)$, balance $(U=2785,5 ; p=.012)$ and perceived control $(U=2850,0 ; p=.049)$ yielded significant differences, whereas clear goals, concentration and absorption did not differ significantly.

\section{Obtaining enjoyment}

According to our theoretical framework, enjoyment can be obtained through absorption in an intrinsically motivated activity. In fact, enjoyment correlated with all the Figure 1 variables relevant to intrinsic motivation: family musical cultural capital $\left(\mathrm{r}_{\mathrm{s}}=.34 ; \mathrm{p}=.000\right)$, a liking for musical practice $\left(\mathrm{r}_{\mathrm{s}}=.39 ; \mathrm{p}=.000\right)$, interest in musical practice $\left(\mathrm{r}_{\mathrm{s}}=.32 ; \mathrm{p}=.000\right)$, and willingness to practice music $\left(\mathrm{r}_{\mathrm{s}}=\right.$. $45 ; \mathrm{p}=.000)$. It also correlated with all the Figure 2 variables relevant to absorption: concentration $\left(\mathrm{r}_{\mathrm{s}}=.44 ; \mathrm{p}=.000\right)$, control $\left(\mathrm{r}_{\mathrm{s}}=.34 ; \mathrm{p}=.000\right)$, balance $\left(\mathrm{r}_{\mathrm{s}}=.40 ; \mathrm{p}=.000\right)$, clear goals $\left(\mathrm{r}_{\mathrm{s}}=.44 ; \mathrm{p}=.000\right)$, and feedback $\left(r_{s}=.42 ; p=.000\right)$. Finally, enjoyment was associated with musical activities such as playing an instrument $\left(\mathrm{r}_{\mathrm{s}}=.26 ; \mathrm{p}=.002\right)$ and singing in a choir $\left(\mathrm{r}_{\mathrm{s}}=.18 ; \mathrm{p}=.033\right)$. However, when controlling for family musical cultural capital, the associations of enjoyment with musical practice disappeared, while its correlations with the Figures 1 and 2 variables also decreased but remained significant, except for feedback, which did not correlate. 


\section{Discussion}

\section{Family musical cultural capital, habitus and flow in primary school music participation}

There is greater evidence for music participation and optimal experience in musical practice among children from families with high musical cultural capital (Table 1). Furthermore, family musical cultural capital correlated with all patterns of musical practice and concert attendance analysed, as well as with all three main components of optimal experience (Table 2). The fact that family musical cultural capital correlated with both enjoyment during school musical practice and music participation suggests that, as discussed by DiMaggio (1982) in relation to Bourdieu's model of cultural reproduction, it is possible to hypothesize that pupils from families with high levels of musical cultural capital, with a corresponding 'musical habitus', obtain greater benefit from their engagement in music participation. Defining this benefit as the achievement of optimal experience in school musical practice and on-going engagement in music participation (Table 1), the hypothesis stood up to the test in our sample: children from 'musical' families scored higher in terms of both enjoyment and engagement. This should not be misconstrued as a mechanistic model, but consideration should certainly be given to the divergences in children's attitudes, resources and strategies with regard to musical practice depending on their different family backgrounds. Moreover, musical practice turned out to be more strongly related to family musical cultural capital than to optimal experience in school musical practice (Table 2), which suggests that a significant amount of the variance in musical practice may be accounted for by family background, possibly more than what can be explained by optimal experience in school itself. This implies that family musical cultural capital is a variable with a notable influence on the potential impact of primary school musical practice on the development of habits of music participation. Family background and its corresponding 'habitus' may play critical roles in optimal experience, as is well expressed by the fact that, when controlling for family musical cultural capital, associations between flow and musical practice disappear. 


\section{The onset of intrinsic motivation}

Family musical cultural capital also proved to be a key issue in this respect. On examining the onset of intrinsic motivation as the cornerstone of optimal experience, we found that the strongest and most significant correlations for intrinsic motivation towards musical practice were the willingness to practice music and positive attitudes towards music (Figure 1), which both correlated with family musical cultural capital, with children from 'musical families' reporting significantly higher values than those from 'non-musical families', as confirmed by nonparametric Mann-Whitney comparisons. As suggested in the theoretical framework, family background and family musical cultural capital can influence the formation of a 'habitus' comprising positive attitudes towards music, which can in turn influence willingness to participate and intrinsic motivation towards musical practice. Based on the fact that adjacent pairs of variables in our theoretical model showed a stronger and more significant correlation with each other than other pairs of variables farther apart in the model, the tenets of construct validity suggest that the distinct steps leading to the onset of intrinsic motivation towards music participation have been correctly assessed.

Additionally, the role of willingness to practice music deserves attention. Even when the correlations between flow measures and the psychological factors involved in the onset of intrinsic motivation (Figure 1) were controlled for family background, willingness to practice music continued to correlate with the two positive attitudes which precede it in the theoretical model, general interest in music and a liking for musical practice, and with all three main components of optimal experience, including absorption. This finding is crucial to understanding the critical importance of children's voluntary investment in a special kind of attention needed to reach the state of optimal experience (Csikszentmihalyi, 1991), and the pedagogic approach taken by music teachers needs to take into account children who are already willing to participate, as well as motivating those who show reluctance. First of all, the teacher has to strengthen identification, intrinsic motivation, interest, and a liking for musical practice. Following this, the teacher has to 
provide clear, attainable goals, feedback and support, in order to foster absorption through its components of balance, control and concentration. The teacher should bear in mind that the two aforesaid processes require separate treatment and also that they are affected differently by the diverse family backgrounds.

\section{The process leading to absorption}

The model displayed an analogous pattern of strong adjacent correlations as regards the variables leading to absorption (Figure 2), clear goals, feedback, concentration, balance and control. Nevertheless, not all Figure 2 variables correlated with family musical cultural capital, in contrast to Figure 1. Family musical cultural capital did not correlate with concentration or clear goals, possibly because in both cases their influence manifests itself regardless of the musicality of the 'habitus', but it did correlate with perceived feedback, balance and control, the more subjective aspects involved in the experience of absorption, which can readily be influenced by the 'habitus' or a personal sense of what is comfortable and natural. It is highly probable that pupils born into families with higher levels of musical cultural capital experience early contact with music within the immediate family milieu, giving them a head start when it comes to accumulating such capital. Moreover, positive attitudes towards music and its practice may be acquired through the family in the ways suggested by Mead (1934) and Bourdieu (1977a), and as a result children do not begin primary school music class in equal conditions as regards a 'feel for the game' (Bourdieu, 1990b, 66) or, as described by Wiggins $(2011,355)$, a 'sense of personal agency' when learning music.

Judging by the fact that out of the three components of flow, absorption was the one with the lowest reported scores (Table 1), and that it was the one that displayed the fewest and least significant correlations with patterns of music participation (Table 2), generating this particular component of flow would appear to be the most challenging part of a primary school music teacher's work. There are three possible explanations for this: firstly, because, as highlighted by 
Lamont (2011), children are initially motivated by extrinsic reasons; secondly, because some children may display especially low levels of intrinsic motivation towards musical practice, owing to negative attitudes or constraints within their family milieu; and lastly, because attaining absorption may ultimately only be dependent on personal willingness to invest in that kind of attention.

\section{How can the music teacher foster 'new' musical cultural capital and sustained engagement musical practice?}

The extent to which new cultural capital can be developed within primary school music education remains a crucial research question and careful experimental design is needed to address it. However, judging by the fact that, when controlling for family background, music participation did not correlate with flow in school musical practice, it looks as if the music teachers' ability to generate fresh engagement in musical practice is severely conditioned by each family's habitus. Through the provision of attitudes and dispositions, the family certainly plays a central role in promoting intrinsic motivation towards musical practice.

However, an analysis of enjoyment in school musical practice showed that it still correlated with all the aspects involved in the onset of intrinsic motivation (Figure 1), even after controlling for family background. Therefore, it is possible to hypothesize that enjoyment operates not only as a variable that may be the outcome of a successful experience in musical practice but also as a new input that reinforces positive attitudes and openness to later music participation for children from families of lower levels of musical cultural capital.

Taking into account Burnard's (2012) descriptions of diverse musical creativities and McIntyre's (2007) explanations of both the circular causality of autotelic experience and the relations between 'person, domain and field', music teachers should embrace innovative approaches and mediums to provide pupils from families possessing lower musical cultural capital from the 
western tradition with positive experiences which will improve their attitude towards musical practice. School musical practice should also get families involved in participative musical activities so as to create a culture-friendly, opportunity-rich environment, as advocated by Kröner and Dickhäuser (2009). This gives parents an opportunity to redefine themselves through greater cultural participation and helps them to build up a repertoire of cultural and musical experiences, which gives their children an opportunity to identify with them in a musical context (Ilari, Moura and Bourscheidt, 2011), thus enhancing their willingness to practice music and intrinsic motivation towards musical practice.

To contend that it is possible for children from non-musical homes to develop their music participation habits through the enjoyment of school musical practice, we focus our attention on the role of willingness to practice music, for it can account for a sustained engagement, becoming a gateway into musical practice as serious leisure (Stebbins, 2001) and consequently into the possibilities and strategies for building up musical cultural capital. We admit to the fact that willingness to practice music alone cannot account for the development of musical cultural capital, however it is likely that it plays an important role in promoting a voluntary investment in a certain kind of deep and exclusive attention on the task at hand (Csikszentmihalyi, 1991), leading to the incorporation of cultural capital indispensable for musical practice. In our model, willingness to practice music played a critical and pivotal role between the attitudes towards music related to the family 'habitus' and intrinsic motivation as a key component of optimal experience. Moreover, willingness to practice music remained correlated to enjoyment in school musical practice even after controlling for family background, which underlines its role in fostering new musical cultural capital through enjoyment and willingness to remain engaged in practice. Nevertheless, as reported earlier, when controlling for family background, enjoyment in school musical practice still correlated with willingness to practice music, whereas it was sustained engagement in musical practice of our primary school pupils which did not correlate with enjoyment or any other measure 
of flow in primary school musical practice. This fact again questions the extent to which it is possible for primary school music teachers to foster 'new' musical cultural capital and a 'new' autonomous engagement in musical practice, when there is originally none in the family, or when the family is not supportive of this practice.

\section{References}

Bakker, A.B. 2001. Questionnaire for the Assessment of Work-Related Flow (WOLF). Department of Social and Organizational Psychology, Utrecht University, The Netherlands.

Bakker, A.B. 2005. Flow among music teachers and their pupils: The crossover of peak experiences. Journal of Vocational Behavior 66, no. 1: 26-44.

Bourdieu, P. 1977a. Cultural reproduction and social reproduction. In Power and ideology in education, ed. J. Karable and A.H. Halsey, 487-511. New York: Oxford University Press.

Bourdieu, P. 1977b. Outline of a Theory of Practice (trans. Richard Nice). Cambridge: Cambridge University Press. (Originally published in French as Esquisse d'une theorie de la pratique in 1972.)

Bourdieu, P. 1990a. In Other Words: Essays towards a reflexive Sociology (trans. Matthew Adamson). Stanford, California: Stanford University Press. (Originally published in French as Choses dites in 1987.)

Bourdieu, P. 1990b. The Logic of Practice (trans. Richard Nice). Cambridge: Polity Press. (Original work Le sens pratique published in 1980).

Bourdieu, P., and J.C. Passeron. 1990. Reproduction in education, society, and culture. London: Sage.

Bouveresse, J. 1999. Rules, Dispositions, and the Habitus. In Bourdieu: A Critical Reader, ed. R. Shusterman, 45-63. Oxford: Blackwell Publishers Ltd.

Burnard, P. 2012. Musical Creativities in Practice. Oxford: Oxford University Press.

Csikszentmihalyi, M. 1988. Optimal Experience. Psychological studies of flow in consciousness. Cambridge: Cambridge University Press.

Csikszentmihalyi, M. 1991. Flow: the psychology of optimal experience. San Francisco: Harper Perennial.

Deci, E.L. 1971. Effects of Externally Mediated Rewards on Intrinsic Motivation. Journal of Personality and Social Psychology 18, no. 1: 105-115. 
DiMaggio, P. 1982. Cultural Capital and School Success: The Impact of Status Culture Participation on the Grades of U.S. High School Pupils. American Sociological Review 47, no. 2: 189-201.

French, J.R.P., Jr., Caplan, R.D., and Harrison, R.V. 1982. The mechanisms of job stress and strain. New York: Wiley.

Ilari, B., A. Moura and L. Bourscheidt. 2011. Between interactions and commodities: musical parenting of infants and toddlers in Brazil. Music Education Research 13, no. 1: 51-67.

Kröner, S. and O. Dickhäuser. 2009. Die Rolle von Eltern, Peers und intrinsischem Wert für die rezeptive hochkulturelle Praxis von Gymnasiasten der Sekundarstufe II. Zeitschrift für Pädagogische Psychologie 23, no. 1: 53-63.

Lamont, A. 2011. The beat goes on: music education, identity and lifelong learning. Music Education Research 13, no. 4: 369-388.

Margolis, J. 1999. Pierre Bourdieu: Habitus and the Logic of Practice, In Bourdieu: A Critical Reader, ed. R. Shusterman, 64-83. Oxford: Blackwell Publishers Ltd.

Martin, A.J., and S.A. Jackson. 2008. Brief approaches to assessing task absorption and enhanced subjective experience: examining 'short' and 'core' flow in diverse performance domains. Motivation and Emotion 32, no. 3.

McIntyre, P. 2007. "Rethinking Creative Practice in the Light of Mihaly Csikszentmihalyi's Systems Model of Creativity." Paper presented at the 3rd Global Conference on Creative Engagements - Thinking with Children, Sidney, February 9-11. Phil Fitzsimmons and Rob Fisher eds. 2007. Oxfordshire, Inter-disciplinary.Net. Accessed February 12, 2014. http://inter-disciplinary.net/ati/education/cp/ce3/ McIntyreP\%20paper.pdf

Mead, G. H. 1934. Mind, self and society. From the standpoint of a social behaviourism. Chicago, IL: The University of Chicago Press

Moore, G. 2012. 'Tristan chords and random scores': exploring undergraduate pupils' experiences of music in higher education through the lens of Bourdieu. Music Education Research 14, no. 1: 63-78.

Stebbins, R. 1992. Amateurs, Professionals and Serious Leisure. Montreal: McGill Queens University Press.

Stebbins, R. 2001. New Directions in the theory and research of serious leisure: Cambridge. Mellen Edwin Press.

Wiggins, J. 2011. Vulnerability and agency in being and becoming a musician. Music Education Research 13, no. 4: $355-367$ 
I.'non musician' II. 'musician' family

\begin{tabular}{lllllcccc} 
& \multicolumn{4}{c}{ family } & \multicolumn{3}{c}{ average } & \multicolumn{2}{c}{ Mann Whitney } \\
\hline Flow & $n$ & $M$ & $s$ & $n$ & $M$ & $s$ & $\mathrm{Z}$ & $p$ \\
1. Intrinsic motivation & 83 & 4,42 & 1,54 & 82 & 4,92 & 1,39 & $-2,319$ &, 020 \\
2. Absorption & 86 & 4,04 & 1,53 & 83 & 4,36 & 1,62 & $-1,757$ &, 079 \\
3. Enjoyment & 83 & 4,63 & 1,23 & 83 & 5,23 & 1,07 & $-3,601$ &, 000 \\
4. Flow average & 82 & 4,36 & 1,15 & 82 & 4,82 & 1,06 & $-2,865$ &, 004 \\
& & & & & & & & \\
Music Participation & $n$ & $M$ & $s$ & $n$ & $M$ & $s$ & $Z$ & $p$ \\
5. Plays an instrument & 72 & 0,69 & 0,46 & 65 & 0,89 & 0,31 & $-2,821$ &, 005 \\
6. Sings in a choir & 71 & 0,47 & 0,50 & 65 & 0,63 & 0,49 & $-1,934$ &, 053 \\
7. Popular music concert & 87 & 0,60 & 0,49 & 72 & 0,81 & 0,40 & $-2,817$ &, 005 \\
8. Classical music concert & 83 & 0,46 & 0,50 & 70 & 0,74 & 0,44 & $-3,557$ &, 000 \\
\hline
\end{tabular}

Table 1: Pupil flow and pupil music participation in relation to family musical cultural capital

\begin{tabular}{|c|c|c|c|c|c|c|c|c|c|c|c|c|c|c|c|c|}
\hline & $n$ & 1 & $n$ & 2 & $n$ & 3 & $n$ & 4 & $n$ & $\begin{array}{c}\text { Plays an } \\
\text { instrumen } \\
t\end{array}$ & $n$ & $\begin{array}{l}\text { Sings in } \\
\text { a clooir }\end{array}$ & $n$ & $\begin{array}{l}\text { Popular } \\
\text { music } \\
\text { concert }\end{array}$ & $n$ & $\begin{array}{c}\text { Classical } \\
\text { music } \\
\text { concert }\end{array}$ \\
\hline $\begin{array}{l}\text { 1. Intrinsic } \\
\text { motivation }\end{array}$ & 178 & 1 & & & & & & & 136 &, 153 & 135 &, 122 & 156 & $219^{\circ *}$ & 150 &,- 002 \\
\hline 2. Absorption & 178 & $401^{* *}$ & 182 & 1 & & & & & 139 & .157 & 138 &, 101 & 159 & $215^{*+}$ & 153 & .070 \\
\hline 3. Enjoyment & 17 & $538+*$ & 179 & $514^{*} *$ & 179 & 1 & & & 136 & $263^{* *}$ & 135 & $.184^{\circ}$ & 156 & $267 * *$ & 150 & 030 \\
\hline 4. Flow average & 177 & $.763^{\circ+}$ & 177 & $842^{\circ+*}$ & 177 & $.762^{*+}$ & 177 & 1 & 135 & $.222^{* *}$ & 134 &, 160 & 155 & $.296^{\mathrm{*}+}$ & 149 & 049 \\
\hline $\begin{array}{l}\text { 5. Family } \\
\text { musical cultural }\end{array}$ & 165 & $.186^{\circ}$ & 169 &, 119 & 166 & $.344^{*}+$ & 164 & $234 * *$ & 137 & $270^{\circ} *$ & 136 & $.185^{\circ}$ & 159 & $.226^{*}+$ & 153 & $.254^{\circ *}$ \\
\hline
\end{tabular}

Table 2: Spearman correlations between flow in musical practice, family musical cultural capital and music participation 


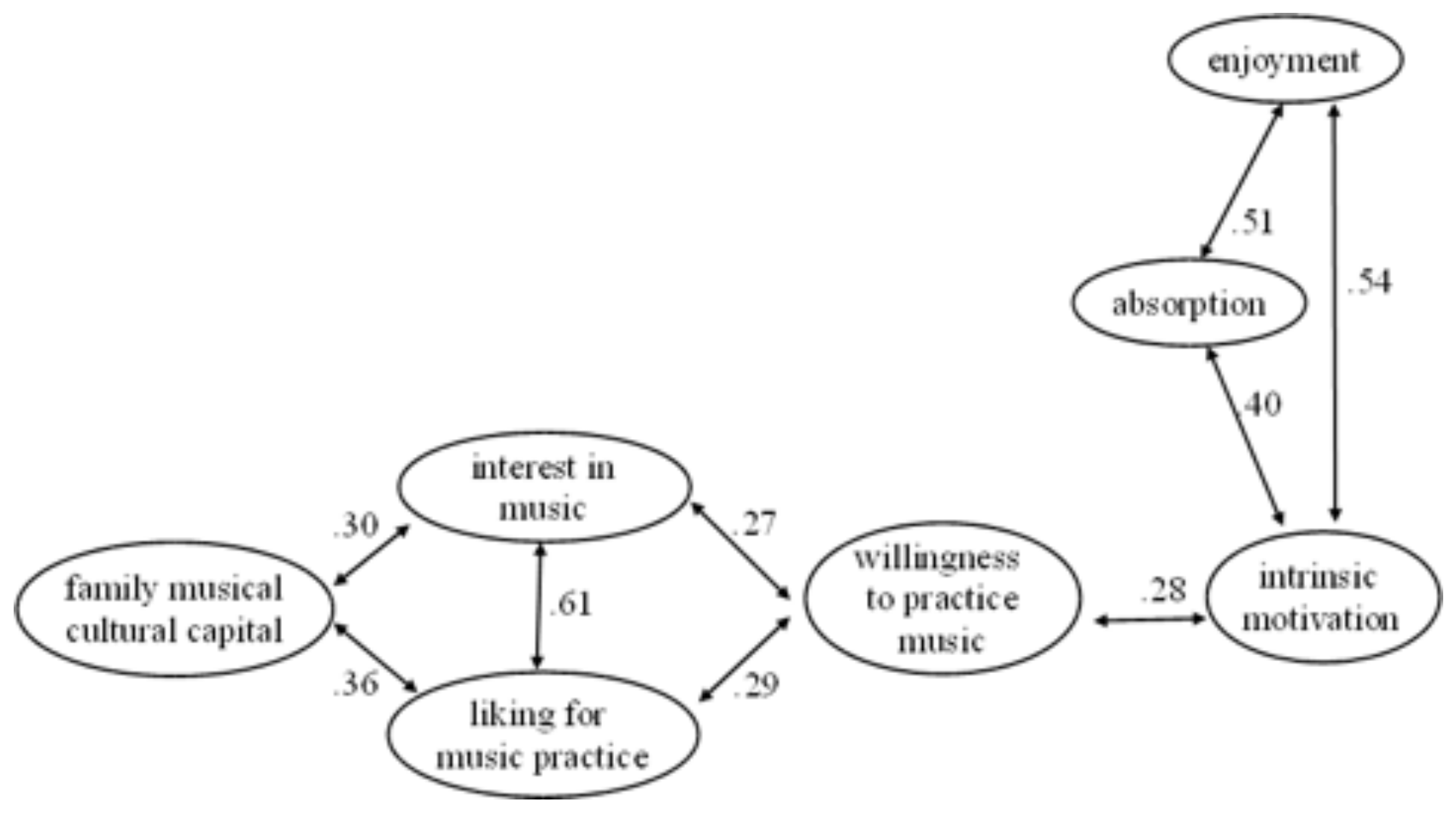

Figure 1: The onset of intrinsic motivation

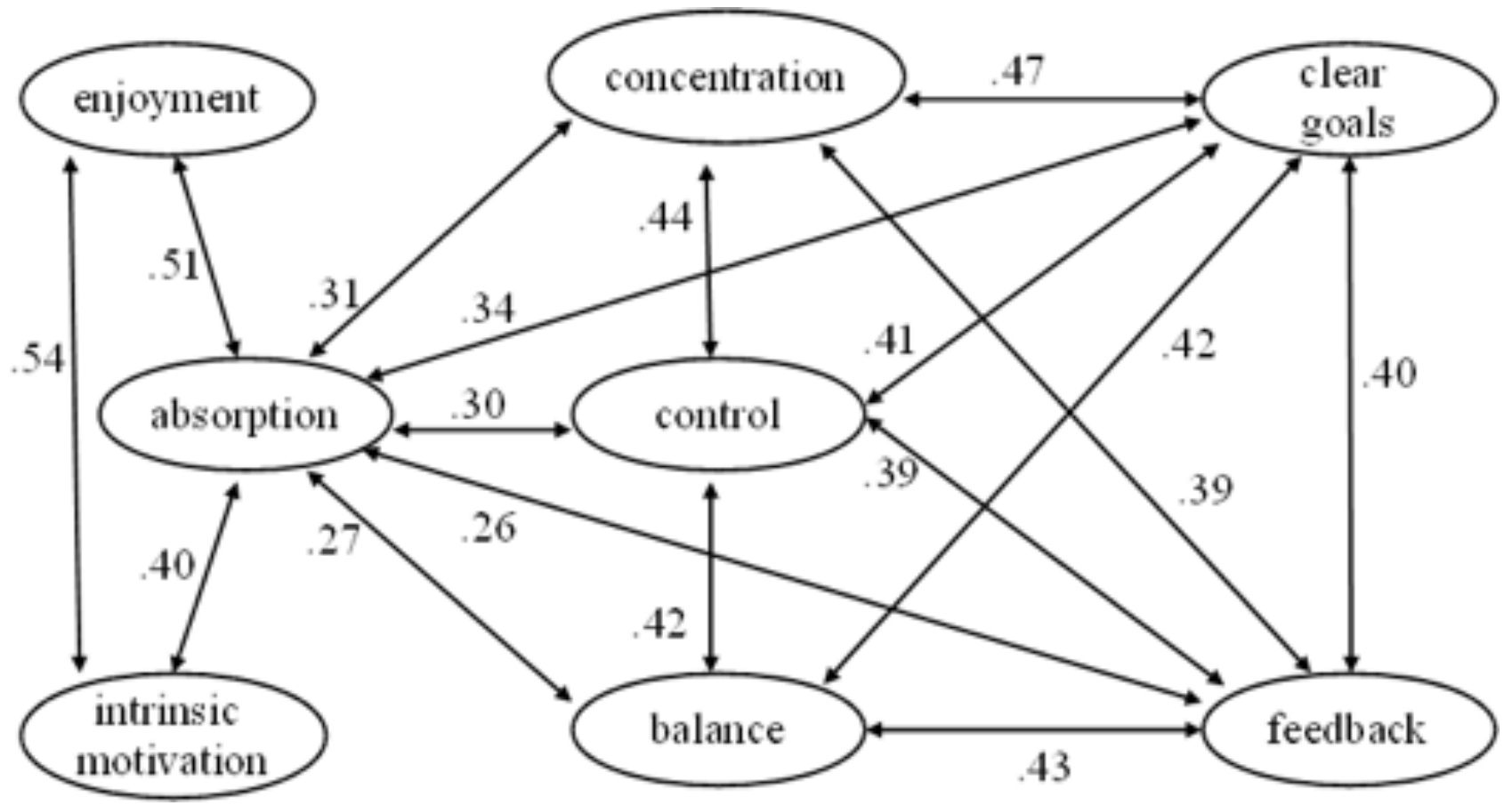

Figure 2: The process leading to absorption 